\title{
Transcriptional profiling of inductive mesenchyme to identify molecules involved in prostate development and disease Griet Vanpoucke ${ }^{\alpha^{*}}$, Brigid Orr ${ }^{\alpha^{*}}$, O Cathal Grace ${ }^{*}$, Ray Chan*, George R Ashley ${ }^{*}$, Karin Williams ${ }^{\dagger}$, Omar E Franco ${ }^{\dagger}$, Simon W Hayward ${ }^{\dagger}$ and Axel A Thomson*
}

\author{
Addresses: * MRC Human Reproductive Sciences Unit, The Queens Medical Research Institute, Little France Crescent, Edinburgh EH16 4TJ, \\ UK. 'Departments of Urologic Surgery and Cancer Biology, Vanderbilt University Medical Center, 21st Avenue South, Nashville, TN 37232- \\ 2765, USA. \\ $\bowtie$ These authors contributed equally to this work.
}

Correspondence: Axel A Thomson. Email: a.thomson@hrsu.mrc.ac.uk

Published: 8 October 2007

Genome Biology 2007, 8:R213 (doi:10.1 I86/gb-2007-8-10-r213)

The electronic version of this article is the complete one and can be found online at http://genomebiology.com/2007/8/I0/R2 I3
Received: 30 March 2007

Revised: 31 May 2007

Accepted: 8 October 2007

(C) 2007 Vanpoucke et al.; licensee BioMed Central Ltd.

This is an open access article distributed under the terms of the Creative Commons Attribution License (http://creativecommons.org/licenses/by/2.0), which permits unrestricted use, distribution, and reproduction in any medium, provided the original work is properly cited.

\begin{abstract}
Background: The mesenchymal compartment plays a key role in organogenesis, and cells within the mesenchyme/stroma are a source of potent molecules that control epithelia during development and tumorigenesis. We used serial analysis of gene expression (SAGE) to profile a key subset of prostatic mesenchyme that regulates prostate development and is enriched for growthregulatory molecules.

Results: SAGE libraries were constructed from prostatic inductive mesenchyme and from the complete prostatic rudiment (including inductive mesenchyme, epithelium, and smooth muscle). By comparing these two SAGE libraries, we generated a list of 219 transcripts that were enriched or specific to inductive mesenchyme and that may act as mesenchymal regulators of organogenesis and tumorigenesis. We identified Scubel as enriched in inductive mesenchyme from the list of 219 transcripts; also, quantitative RT-PCR and whole-mount in situ hybridization revealed Scubel to exhibit a highly restricted expression pattern. The expression of Scube $I$ in a subset of mesenchymal cells suggests a role in prostatic induction and branching morphogenesis. Additionally, Scubel transcripts were expressed in prostate cancer stromal cells, and were less abundant in cancer associated fibroblasts relative to matched normal prostate fibroblasts.

Conclusion: The use of a precisely defined subset of cells and a back-comparison approach allowed us to identify rare mRNAs that could be overlooked using other approaches. We propose that Scubel encodes a novel stromal molecule that is involved in prostate development and tumorigenesis.
\end{abstract}




\section{Background}

The mesenchymal compartment is involved in the induction and organogenesis of various organs, including lung, limb, kidney, pancreas, prostate, and mammary gland. In general, the process of organ induction begins with the formation of a specialized area of mesenchyme that acts upon adjacent epithelia to specify organ identity and subsequently dictates epithelial morphogenesis into the required form and function within the organ. The role played by inductive mesenchyme has been established using classical embryologic methods such as tissue recombination and engraftment, which have assayed the ability of spatially defined areas of mesenchyme to control morphogenesis and organogenesis. During organogenesis reciprocal interactions and signaling occur between the mesenchymal and epithelial compartments; in addition, numerous paracrine and autocrine growth regulatory pathways such as Wnt, hedgehog, fibroblast growth factor (FGF), Notch, and transforming growth factor- $\beta$ are also active. The inductive mesenchyme involved in organ induction goes on to form signaling centers that are involved in growth and differentiation as well as specialized functions such as branching morphogenesis. At present, our knowledge of the pathways that are active in inductive mesenchyme is limited; this may be because of the inherently small size of these mesenchyma and a lack of suitable markers. It is likely that the proportion of inductive or specialized mesenchyme within a developing organ is low, which will make it difficult to isolate sufficient material for profiling studies.

The prostate develops from the embryonic urogenital sinus in response to testicular androgens and as a result of reciprocal mesenchymal epithelial interactions (for review [1]). Paracrine signaling from the urogenital mesenchyme (UGM) to the epithelium specifies prostatic epithelial identity, induces epithelial bud formation and growth, and regulates ductal branching morphogenesis (for review [2]). Androgen action within the urogenital sinus mesenchyme was originally defined as being necessary and sufficient for prostate organogenesis; androgen action in the epithelia is not required [3,4]. Within the mesenchyme a distinct area of mesenchyme has been defined that regulates prostatic organogenesis [5]. This mesenchyme has been termed the ventral mesenchymal pad (VMP), based on its anatomic position. However, it appears that the VMP is part of a structure that encircles the urethra and may participate in the formation of all lobes of the prostate. Additionally, it appears that the VMP is better anatomically defined in rat than in mouse, although it can be distinguished by its restricted expression of molecules such as FGF10 and bone morphogenetic protein (BMP)4 [6,7]. The VMP is present in both males and females, suggesting that androgens are not required for its formation [5,8], although androgens are required for prostate induction and organogenesis. The activity of molecules produced in the VMP may be indirectly regulated by androgens that control the formation of a layer of smooth muscle that is juxtaposed between the VMP and urethral epithelium [8,9]. The VMP constitu- tively expresses key growth regulatory molecules such as FGF10, which functions as a mesenchymal paracrine regulator of prostatic epithelia and is essential for the formation of the prostate [10].

Androgens are required for the formation of the prostate, and there has been considerable interest in defining the pathways that might be involved in mediating the effects of androgens. Furthermore, because androgen receptor activity is required in the mesenchyme/stroma, this has led to the idea that androgens may act through paracrine factors produced in the mesenchyme. At present there are no molecules that are expressed in the mesenchyme which show clear upregulation by androgens, despite a range of experimental approaches. It is also possible that androgens may not directly control the expression of paracrine acting factors but may act indirectly, by controlling the interaction of inductive mesenchmye with epithelia via the smooth muscle compartment. In the developing reproductive tract there is a sexually dimorphic layer of smooth muscle that separates inductive prostatic mesenchyme (VMP) from the urethral epithelium (from which nascent prostatic buds will form). In females this layer forms rapidly and isolates the VMP, but in males the layer remains discontinuous to permit interaction of the VMP with epithelia [8]. It appears that the smooth muscle patterning is controlled by androgens and estrogens [9]. The hypothesis that androgens act via the smooth muscle compartment would suggest that androgens may not directly regulate the expression of paracrine factors in the mesenchyme. This is supported by the observation that factors such as FGF10, which are required for the formation of the prostate, are equally abundant in males and females and do not appear to be regulated by testosterone $[7,11]$.

The question of which genes are involved in androgen-driven growth of the prostate has led to several studies that have used arrays to examine the gene expression profile of the prostate and prostate cell lines. Such studies have used either whole prostate [12-15], prostate tumor samples [16-19], or prostate cell lines [20]. There is limited similarity between these datasets, which probably reflects the different nature of the tissues as well as the cellular heterogeneity in some of the tissues and samples. It may be hoped that a few genes were common to all studies, or within individual studies, that might identify mediators of androgen action upon growth. However, few or none appear to exhibit such a pattern. Additionally, it may be that only a subset of cells are the target of androgen action, in which case the identification of the gene expression signature of these cells within a complex tissue may be difficult [21]. This will be particularly difficult for lowabundance transcripts expressed in subsets of cells and in rare cells such as progenitor/stem cells.

It has recently become apparent that the stroma is also actively involved in neoplastic prostate growth (for review [22]). Tumor-associated stroma or reactive stroma exhibits a 
variety of phenotypic and functional differences relative to normal stroma (for review [23,24]). The tumor stroma is no longer able to restrain prostatic epithelial proliferation, but instead carcinoma-associated fibroblasts stimulate epithelial tumor growth $[25,26]$ and stimulate tumor angiogenesis [27]. The role of stroma in prostate tumor growth is highly reminiscent of the developmental growth of the prostate, and developmental pathways have been identified in prostate tumor stromal cells [28]. This notion of developmental pathway involvement in tumorigenesis was pioneered by Pierce several years ago [29].

We have used an unbiased approach to identify new stromal regulators of prostate growth. Our thesis was that mesenchymal factors that are involved in prostatic induction would be constitutively expressed in either males or females, as predicted by the 'smooth muscle' hypothesis described above. Additionally, we speculated that our approach might identify potential 'andromedin' molecules if they were expressed at low levels in females, because females are exposed to low (nonmasculinizing) levels of androgens in vivo. Similarly, we thought that a highly sensitive approach would identify androgen regulated molecules at their un-induced levels in the female prostatic rudiment.

Using serial analysis of gene expression (SAGE) we profiled a subset of urogenital mesenchymal cells that comprise the VMP [30]. The VMP is a homogenous subset of mesenchymal cells that initiates and regulates prostate organogenesis, and which can be microdissected in sufficient quantity for SAGE library construction. In addition, we constructed a SAGE library of the whole prostatic precursor, comprising the VMP, smooth muscle and urethral epithelium (VSU). By comparing the two SAGE libraries, we hoped to identify molecules enriched or restricted to the VMP while eliminating those expressed throughout all tissues (such as housekeeping genes and genes expressed in smooth muscle and epithelium). Our SAGE library comparison yielded a list of 219 transcripts, which exhibited a statistically significant enrichment in the VMP compared with the whole precursor (VSU). Most of the 219 transcripts were identified by low frequency tags in the SAGE libraries, suggesting that they were derived from lowabundance transcripts. One of the molecules we identified was Scube1 [31]. We demonstrate that Scube1 is expressed during prostate induction and branching morphogenesis, and that it is restricted to a subset of prostatic mesenchyme including the VMP. Expression of Scube1 was not affected by androgens and was observed in both males and females. Additionally, Scube1 mRNA was expressed in prostate cancer stromal cells, and was downregulated in cancer-associated fibroblasts relative to normal prostate fibroblasts. We propose that the list of 219 transcripts that we have identified may contain several mesenchymal factors that are important during organogenesis and tumorigenesis.

\section{Results \\ SAGE analysis of prostatic inductive mesenchyme}

To determine the transcript profile of prostatic inductive mesenchyme, we applied SAGE to a subset of the prostatic mesenchyme, namely the VMP. We constructed two SAGE libraries (Figure 1): one consisted purely of the VMP, whereas the second library (VSU) was composed of the whole prostatic precursor tissue containing VMP, smooth muscle, urethral epithelium and mesenchyme.

The area of the urogenital tract (UGT) dissected for library construction is shown in Figure 1a; the VMP can be seen as a sub-area of the VSU and both are outlined to illustrate the starting material for the libraries. The VSU library is made from a more complex tissue than the VMP library, and as a consequence, if both libraries are sequenced to a similar depth, VMP-specific transcripts will exhibit greater abundance in the VMP-only library. Our hypothesis was that transcripts expressed in the VMP would be 'diluted' in the VSU library (because the VMP is included as a component of the VSU). This effect would be most pronounced with regard to transcripts that were present at low abundance in the VMP and very low or absent in the VSU library. By comparing the VSU and VMP libraries and selecting for the tags with a significantly higher tag count in the VMP library (Figure 1a), we enriched for low abundance VMP-specific transcripts, while removing most housekeeping genes and broadly expressed transcripts. The number and frequency of tags showing a statistically significant difference between the two libraries is shown in Figure 1b. Datapoints colored red nearest to the VMP axis represent VMP-enriched tags, and these are described further below.

We sequenced about 70,0oo tags for each library, translating into 22,755 and 26,932 distinct tags for the VSU and VMP libraries, respectively. About $68 \%$ of tags were found only once in each SAGE library. A significant proportion of these single tags will have resulted from sequence errors, and thus we excluded them from most subsequent analyses. Analysis of the VMP SAGE data revealed the presence of known mesenchymal regulatory factors in prostate growth, such as FGF10, BMP4, Smoothened and androgen receptor (AR), indicating an adequate sequencing depth to identify known regulators of prostate organogenesis.

\section{VMP-VSU SAGE library comparison to identify inductive mesenchyme specific transcripts}

Comparison of the VMP and VSU SAGE libraries yielded a list of 219 tags that exhibited a significant enrichment in the VMP library (see Additional data file 1). SAGEMAP and genomic basic local alignment search tool (BLAST) were used to assign SAGE tags to specific transcripts and genes. The smallest statistically significant difference between our two SAGE libraries was 5:0 tags in VMP:VSU libraries [32]. Because an important goal of our studies was to identify mesenchymal paracrine factors, we examined our libraries for the presence 


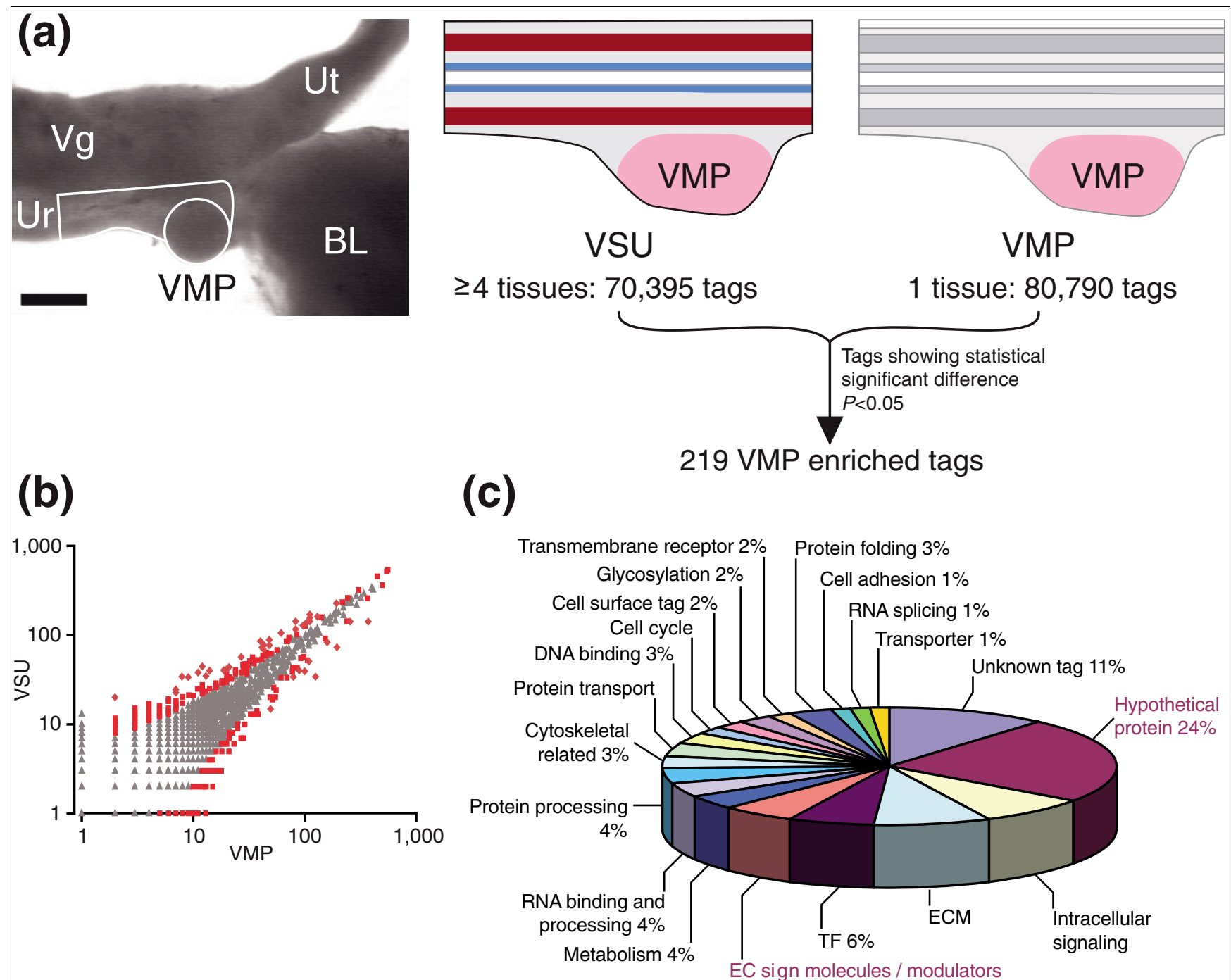

Figure I

SAGE analysis of prostatic inductive mesenchyme. (a) The strategy used in construction and comparison of serial analysis of gene expression (SAGE) libraries to identify ventral mesenchymal pad (VMP) specific or enriched transcripts. PO female urogenital tracts (UGTs) were microdissected to provide either pure VMP or the whole prostatic rudiment (VMP, smooth muscle, urethral epithelium [VSU]); the tissues dissected for library construction are outlined in black. The VMP tissue comprised only the condensed inductive mesenchyme of the VMP, whereas the VSU library contained urethral epithelium, smooth muscle, urethral mesenchyme and VMP. Both VMP and VSU SAGE libraries were sequenced to the indicated total number of tags. Pairwise comparison was performed and 219 tags exhibiting statistically significant enrichment in the VMP were identified. (b) Scatter plot showing the comparison of the VMP and VSU SAGE libraries. Tag frequencies were plotted on a logarithmic scale and $P$ values were calculated using the $Z$ test; tags showing a difference at $P=0.05$ are shown in red. (c) Pie chart depicting functional classification of the 219 VMP identified transcripts; extracellular (EC) signaling modulators and hypothetical proteins were highlighted for further analysis. Bl, bladder; TF, transcription factors; Ur, urethra; Ut, uterus; $\mathrm{Vg}$, vagina; VMP, ventral mesenchymal pad.

of factors known to play a role in prostate development. We detected FGF10 in our VMP library, but it had four tag counts. As a consequence FGF10 was not identified as being VMP enriched in our SAGE screen, which exemplifies a limitation of our bioinformatic comparison. Although our approach identified many low abundance VMP enriched molecules, it inevitably will have missed some because of sampling error, and rare transcripts are most susceptible to sampling error. This is supported by estimation of the statistical power to determine differential expression between the VMP and VSU libraries, which indicates that at power of 0.9 differences of greater than twofold in tags of 50 and above might be detected [33,34]. The majority of transcripts in the VMP list are below this level, and it is likely that we have not identified all of the low abundance transcripts specific to the VMP. Although our analysis identified novel mesenchymal molecules that are involved in prostate organogenesis, it is possible that further such molecules remain to be identified. 
Table I

\begin{tabular}{|c|c|c|c|c|c|}
\hline LONG-SAGE tag & VMP & VSU & Uni-gene & Description (SAGEMAP) & Genomic BLAST \\
\hline CATTTTCTGGCAAAATC & 124 & 34 & 964 & Insulin-like growth factor 2 & \\
\hline CСTAGCСССТСССАССА & 49 & 15 & 7961 & $\begin{array}{l}\text { Rattus norvegicus similar to latent } \\
\text { transforming growth factor- } \beta \text { binding } \\
\text { protein } 4 \text { S (LOC292734), mRNA }\end{array}$ & \\
\hline ATATAATGAATAATAAT & 38 & 13 & 14547 & Delta-like homolog (Drosophila) & \\
\hline GTTTGTACAATAAATAC & 14 & 4 & 37338 & $\begin{array}{l}\text { Latent transforming growth factor- } \beta \text { binding } \\
\text { protein } 3\end{array}$ & \\
\hline GATGAATGTTATATGTT & 12 & 2 & & & $\begin{array}{l}\text { Unique hit, } 2 \mathrm{~kb} \text { from mRIKEN } \\
\text { cDNAI } 200009022\end{array}$ \\
\hline TGAATССТСТСССТАAA & 11 & 2 & 15332 & $\begin{array}{l}\text { R. norvegicus similar to RIKEN cDNA } \\
\text { 9430096L06 (LOC29I8I3), mRNA }\end{array}$ & $\begin{array}{l}\text { Unique hit, close to novel transcript (h } \\
\text { Chemokine like superfamily factor } 3 \text { ) }\end{array}$ \\
\hline TAAAGTCAAAATAAAAT & 11 & I & 8257 & R. norvegicus transcribed sequences & Unique hit, $2 \mathrm{~kb}$ from Semaphorin6D locus \\
\hline TGGGCATAGCTGAGGTG & 10 & 2 & 41133 & R. norvegicus transcribed sequences & $\begin{array}{l}\text { Unique hit, } 2 \mathrm{~kb} \text { from novel transcript with } \\
\text { similarity to } \mathrm{mSorC} 2 \text { precursor (VPSI0 } \\
\text { domain containing receptor }\end{array}$ \\
\hline TAAGAGCTCTTTCCATC & 10 & 1 & 8672 & $\begin{array}{l}\text { R. norvegicus similar to hypothetical protein, } \\
\text { estradiol-induced (LOC308843), mRNA }\end{array}$ & Unique hit, ortholog of chicken Tsukushi \\
\hline TCTGAATATAACATATC & 8 & 1 & 22787 & $\begin{array}{l}\text { R. norvegicus similar to sprouty I } \\
\text { (LOC29498I), mRNA }\end{array}$ & \\
\hline CCGCTTGAGACTCCTTC & 6 & 0 & 25124 & $\begin{array}{l}\text { Rat insulin-like growth factor I mRNA, 3' } \\
\text { end of mRNA }\end{array}$ & \\
\hline GCATAGTCTGAGATGCA & 6 & 0 & 40510 & R. norvegicus transcribed sequences & Unique hit, $2 \mathrm{~kb}$ from Wnt4 locus \\
\hline TTCCTGACTAAATGTAG & 6 & 0 & 65930 & Notch gene homolog 2 (Drosophila) & \\
\hline CCTTGGGGGAGGGTGGG & 5 & 0 & & & Unique hit, I kb from to mSlit2 homolog \\
\hline GGAGATACCTGTTCAAA & 5 & 0 & 11567 & Nel-like 2 homolog (chicken) & \\
\hline TAATTAAACACTTGTGA & 5 & 0 & 103231 & R. norvegicus transcribed sequences & $\begin{array}{l}\text { Unique hit, } 4 \mathrm{~kb} \text { from novel transcript with } \\
\text { homology to } \mathrm{mScubel}\end{array}$ \\
\hline AGTGTGTACAAGCTTAG & 5 & 0 & & & $\begin{array}{l}\text { Unique hit, close to novel transcript similar } \\
\text { to mEphB3 receptor }\end{array}$ \\
\hline
\end{tabular}

BLAST, basic local alignment search tool; kb, kilobases; SAGE, serial analysis of gene expression; VMP, ventral mesenchymal pad; VSU, VMP, smooth muscle and urethral epithelium.

The list of 219 VMP enriched tags/transcripts was functionally classified according to their Gene Ontology (Figure 1c). For approximately $11 \%$ of our list, we were unable to assign transcripts to these tags, but a number of them could represent anti-sense transcripts because they map to the 3'untranslated region of known transcripts but in the antisense orientation (Additional data file 1; anti-sense tags are identified within the 219 list). We chose to focus on transcripts that encode potential growth regulatory molecules or modulators. About 5\% of our list is made up of extracellular signaling molecules, whereas four tags mapped to known transmembrane receptors. We analyzed the large group of hypothetical proteins (25\%) for the presence of signal peptides, transmembrane domains, and functional domains that suggested involvement in cellular signaling activity. As a result we identified a list of 17 putative extracellular or transmembrane signaling molecules that exhibited a significant enrichment in the VMP SAGE library (Table 1).

We examined several members of the VMP-enriched list by quantitative RT-PCR, Northern blot, and whole-mount in situ hybridization to determine whether they could be verified as VMP enriched. The candidates that we chose to examine further included secreted or membrane-bound molecules that might be involved in cell-cell interactions. Of 30 candidates tested, 11 were confirmed as being VMP enriched, 12 were not confirmed, and seven were inconclusive. The transcripts that were validated as VMP enriched were as follows: Igf2, MMP2, Dlk1, Notch 2, Nel-like2, decorin, EphB3 receptor, slit2, sprouty1, mSorC2m, and sema6D. These candidates comprise 11 of the 17 extracellular or transmembrane molecules listed in Table 1. We estimate that approximately one-third of the transcripts in the VMP list may be confirmed as VMP specific by additional follow up, but this will require further experimental validation. Members of the insulin-like growth factor family have been implicated in prostate organogenesis [35,36]. Also, Wnt4 was recently reported to be expressed in developing prostates, but its precise localization was not determined [37]. Our SAGE data revealed the expression of a number of transcription factors that have been implicated in organogenesis of other tissues (for example, PLAG1, Pbx3, and $\mathrm{SOX}_{7}$ ). In addition to intracellular molecules, there was a 
considerable number of extracellular matrix proteins. The VMP consists of mesenchyme that is morphologically distinct from the surrounding mesenchyme. The higher expression of some of these extracellular matrix components may be responsible for the different morphology of the inductive mesenchyme. In general, our VMP-enriched list gives an overview of the transcriptional programs that are active in mesenchyme during prostate organ induction.

\section{Scubel: a new prostate inductive mesenchyme specific gene}

One of the extracellular signaling molecules identified as being VMP enriched by SAGE analysis was Scube1 [31]. Five Scube1 tags were present in the VMP library, whereas none were identified in the VSU library (Figure 2a). The enrichment of Scube1 in VMP RNA was confirmed by both quantitative RT-PCR (Figure 2a; yellow bar) and Northern blot (Figure 2b). Scube1 mRNA was also identified in Po prostate (Figure 2b). Whole-mount RNA in situ hybridization further defined expression of the Scube1 transcript only in the mesenchyme of a Po female UGT, whereas the peri-urethral mesenchyme and the urethral epithelium did not express Scube1 (Figure 2c). Levels of Scube1 expression in the UGT, prostate, and inductive mesenchyme have not previously been reported. Grimmond and coworkers [31] isolated the Scube1 transcript from a cDNA library of the mouse urogenital ridge and reported expression in developing gonads, nervous system, and mesenchyme of developing limb buds. Our Northern blot analysis in Po tissues identified the highest Scube1 expression in testis and ovary, followed by high expression in prostate and brain (Figure 3a). We could barely detect Scube1 in adult tissues (Figure $3 \mathrm{~b}$ and data not shown). It must be noted that there are significant developmental differences in the organs at Po; the prostate is rudimentary and undergoing extensive branching morphogenesis, whereas organs such as lung and kidney are more mature. The expression pattern in rat Po tissues is somewhat different than the reported expression pattern in adult human tissues, which may be due to different developmental stages of organ development [38]. The decrease in Scube1 transcript levels between embryonic and adult stages may be a result of either gene downregulation or loss of the subset of cells that express it, and we cannot be sure which is the primary factor or whether the decrease is a result of both downregulation and loss of cells.

To further examine Scube1 expression in the prostate, we compared Scube1 transcript levels in early UGTs, developing prostate undergoing branching morphogenesis, and mature adult prostate (Figure 3b). Scube1 mRNA levels were most abundant during prostate induction at E17.5 (before bud development), and were high during prostate branching and growth (Po and $\mathrm{P}_{4}$ ). By $\mathrm{P} 10$ there was significant decrease in Scube1 mRNA levels, with very low or undetectable levels by puberty (P28) and in the adult rat. This temporal distribution suggested a role for Scube1 in prostate organogenesis. However, we observed similar levels of Scube1 mRNA in both males and females at E17.5, which suggested that there was no sexually dimorphic difference in Scube1 transcript expression. The Scube1 mRNA encodes a secreted glycoprotein with epidermal growth factor repeats and a CUB domain (a domain first found in complement C1r, C1s, uEGF, and bone morphogenetic protein 1). No function has yet been described for mammalian Scube1, but its domain structure suggests a possible role in growth factor modulation [31]. Studies in zebrafish have suggested that Scube family members may be involved in sonic hedgehog (Shh) signal transduction, and it

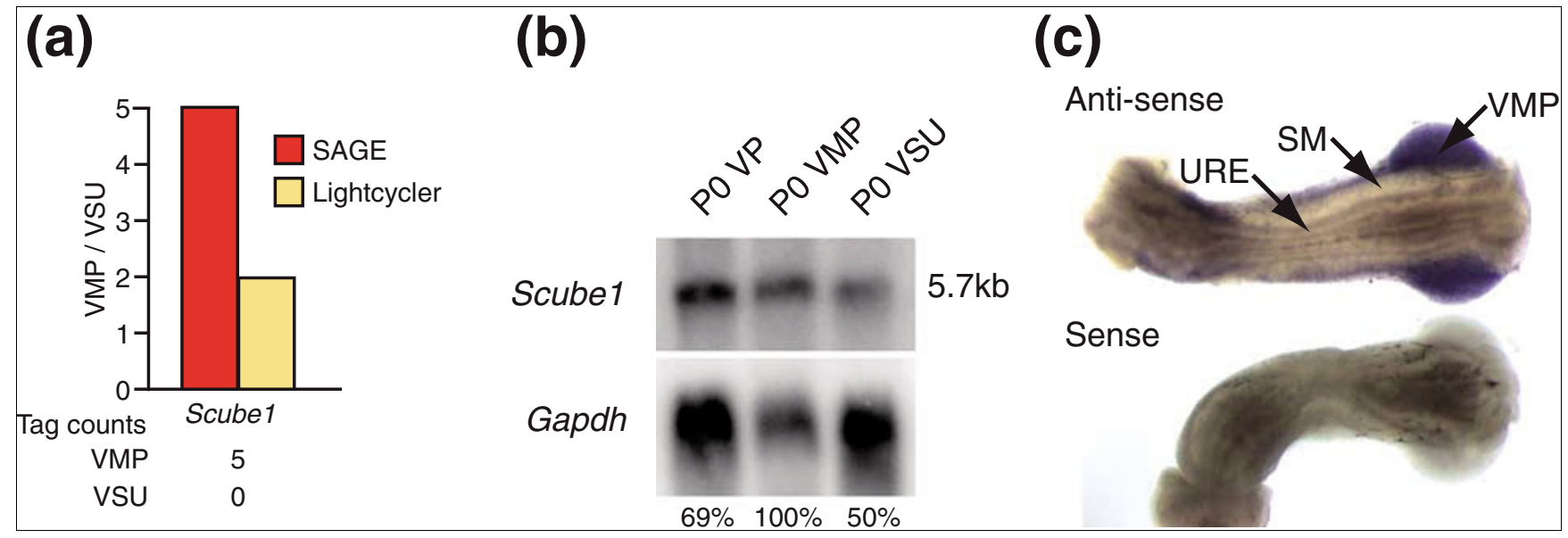

Figure 2

Localization of Scubel to the inductive mesenchyme (VMP) of female UGT. (a) Comparison of Scubel transcript levels in ventral mesenchymal pad (VMP) and VSU (VMP, smooth muscle and urethral epithelium) using serial analysis of gene expression (SAGE) and quantitative RT-PCR. Red bars represent the SAGE data, and yellow bars represent the quantitative RT-PCR data (normalized to TBP levels). Scubel mRNA was found to be enriched in the VMP by both SAGE and quantitative RT-PCR analyses. (b) Northern analysis showing a twofold enrichment of Scube I mRNA levels in the VMP compared with the VSU. (c) RNA whole-mount in situ hybridization of Scubel in PO female UGT; anti-sense probe is at top of panel and sense is at the bottom of the panel. Scubel transcripts localized to the VMP, and were not observed in smooth muscle (SM) and urethral epithelium (URE). 


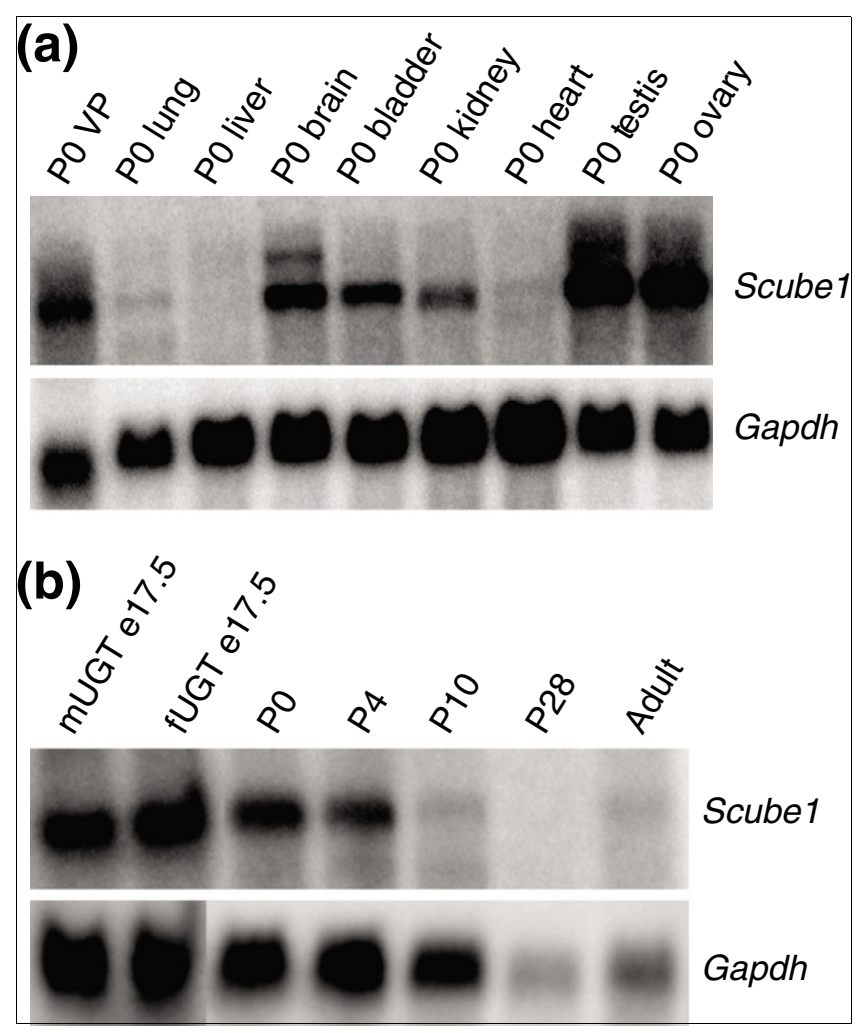

\section{Figure 3}

Expression of Scube I mRNA in rat P0 tissues and during prostate development. (a) Northern blot analysis of Scube I mRNA levels in PO tissues; highest levels of Scubel transcripts were observed in testis and ovary. Brain, ventral prostate (VP), bladder, and kidney showed moderate Scube I expression. Kidney and lung showed very low expression, and liver was negative. (b) Expression of Scube $I$ in male and female urogenital tract (UGT) at EI7.5, and subsequent expression the VP at P0, P4, PIO, P28, and adult.

is possible that Scube may control other extracellular signaling pathways [39,40].

\section{Spatial localization of Scube I mRNA during prostate development}

Some insight into the role played by Scube1 in prostate growth was obtained by defining the cell and tissue compartment expression pattern. Whole-mount in situ hybridization was used to determine the spatial expression pattern of Scube1 at different stages of prostate development. There was robust Scube1 mRNA expression in the urogenital sinus (UGS) during early prostate organogenesis in rat, at fetal day E17.5 (Figure 3b). Shortly after this time point prostatic budding is initiated, when developing epithelial buds penetrate into the surrounding UGM in the dorsal, lateral, and ventral directions. In E18.5 UGTs, Scube1 mRNA was present in the VMP of both males and females (Figure 4a,b), and the patterns of Scube1 expression around the urethra of male and female were very similar. In males, Scube1 transcripts were present in the mesenchyme overlying the position where dor- sal and lateral prostates formed (Figure $4 \mathrm{a}, \mathrm{b}$ ), whereas in females it was also present in the Mullerian duct. The developing seminal vesicles and Wolffian duct structures of male E18.5 UGTs exhibited very little or no Scube1 expression (Figure $4 \mathrm{~b}$ ). In Po male UGTs a similar expression pattern was seen; robust Scube1 mRNA levels were observed in the mesenchyme, whereas the emerging prostatic epithelial ducts were negative for Scube1 (Figure 4c,d). In the dorsolateral prostate the Scube1 signal was strongest in the mesenchyme directly adjacent to the ducts (Figure 4d). Scube1 transcripts were also observed in the mesenchyme of the ventral prostate (VP; Figure 4c,d). Taken together, it appeared that Scube1 was expressed in a specific subset of the mesenchyme, consistent with the VMP tissue used in the construction of the SAGE libraries.

\section{Scube I expression is not regulated by testosterone}

The spatiotemporal localization of Scube1 suggested that it might function as a regulator of prostate growth. To determine whether Scube1 expression was regulated by androgens, we examined whether Scube1 mRNA expression and localiza-
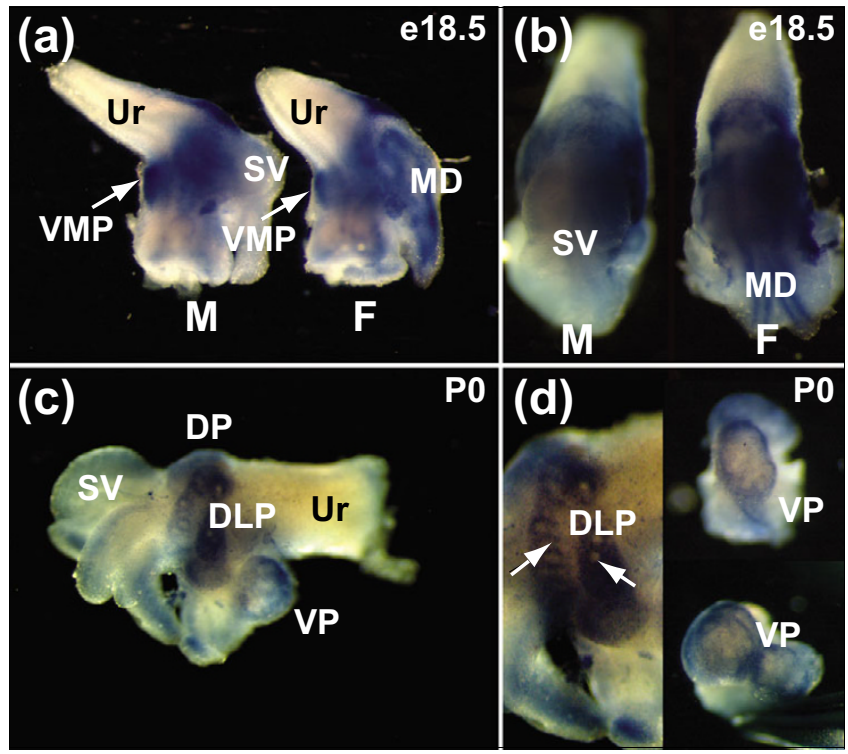

Figure 4

Spatial distribution of Scube I mRNA in male and female UGT. (a,b) Whole-mount in situ hybridization showing Scubel transcript expression in EI8.5 male (M) and female (F) urogenital tract (panel a shows lateral view and panel b shows dorsal view). Scube I mRNA was present in a subset of the urogenital mesenchyme including the VMP (marked by arrows in male and female). In females there was staining in the mesenchyme of the Mullerian duct (MD). In males, the seminal vesicle (SV) mesenchyme showed little or no staining. In both sexes the urethra (Ur) and urethral mesenchyme were negative for Scubel mRNA. (c,d) PO male urogential tract. The mesenchyme of the dorsal prostate (DP), dorsolateral prostate (DLP), and ventral prostate (VP) showed Scubel transcript expression. In panel d, DLP is shown on the left hand side and epithelial buds (arrows; negative for Scubel) can be seen entering the DLP mesenchyme. On the right hand side of panel $d$ ventral prostate is shown, and Scubel transcripts are abundant in the mesenchyme and show enrichment in the peripheral mesenchyme. 
tion were affected by testosterone using male or female UGT rudiments grown in vitro.

Whole-mount RNA in situ hybridization of male VPs grown in the absence or presence of testosterone exhibited little or no change in transcript distribution; Scube1 localized to the inductive mesenchyme surrounding the distal duct tips under both conditions (Figure 5a) and was absent from epithelia. Scube1 mRNA showed slightly increased expression in the mesenchyme at the periphery of the organ, where epithelial proliferation is highest [41]. To quantify changes in Scube1 transcripts we grew VPs in the presence or absence of testosterone and measured transcript levels by quantitative RTPCR (Figure 5b). Treatment of VPs with testosterone had no significant effect on Scube1 or FGF10 mRNAs. To rule out potential carry over of testosterone in cultures of male VPs, we used cultures of Po female UGTs grown in vitro. The rudiments used correspond to the VSU used for SAGE library construction. Treatment of Po female UGTs for 6 or 24 hours with testosterone did not change Scube1 transcript levels, as shown by Northern analysis (Figure 5c). In addition, we examined Scube1 mRNA levels in primary VMP mesenchymal cells grown in vitro [42], and no changes were observed following short-term or long-term treatment with testosterone (data not shown).

Taken together, it appears that androgens do not alter the distribution of Scube1 mRNA in males, or the amount of Scube1 mRNA in either males or females. Furthermore, we did not observe a difference in Scube1 levels between E17.5 male and female embryonic UGTs in vivo (Figure $3 \mathrm{~b}$ ), and we conclude that Scube1 is unlikely to be regulated by androgens.

\section{Scubel expression is downregulated in prostatic cancer-associated fibroblasts compared with normal prostate fibroblasts}

Because Scube1 was specifically expressed in the mesenchyme during development, we examined whether it was present in prostate cancer stroma and whether it was differentially expressed between cancer-associated fibroblasts (CAFs) and normal prostate fibroblasts (NPFs). Scube1 mRNA was examined in five pairs of functionally tested NPF and CAF samples by both Northern analysis and quantitiative RT-CPR. All CAFs had been shown to produce tumors when recombined with an epithelial cell line, whereas all NPF samples did not [26] (and data not shown). Four pairs of CAFs/ NPFs were matched from the same patient, whereas one pair was not.

Scube1 transcripts were identified in all CAFs and NPFs, demonstrating that Scube1 was expressed in prostate cancer stromal cells (Figure 6). Furthermore, in four out of five samples Scube1 was found to be downregulated in the CAFs compared with the NPFs, by both Northern blotting and quantitative RT-PCR (Figure 6). Scube1 downregulation was between 2fold and 20-fold. This decreased expression in CAFs com-

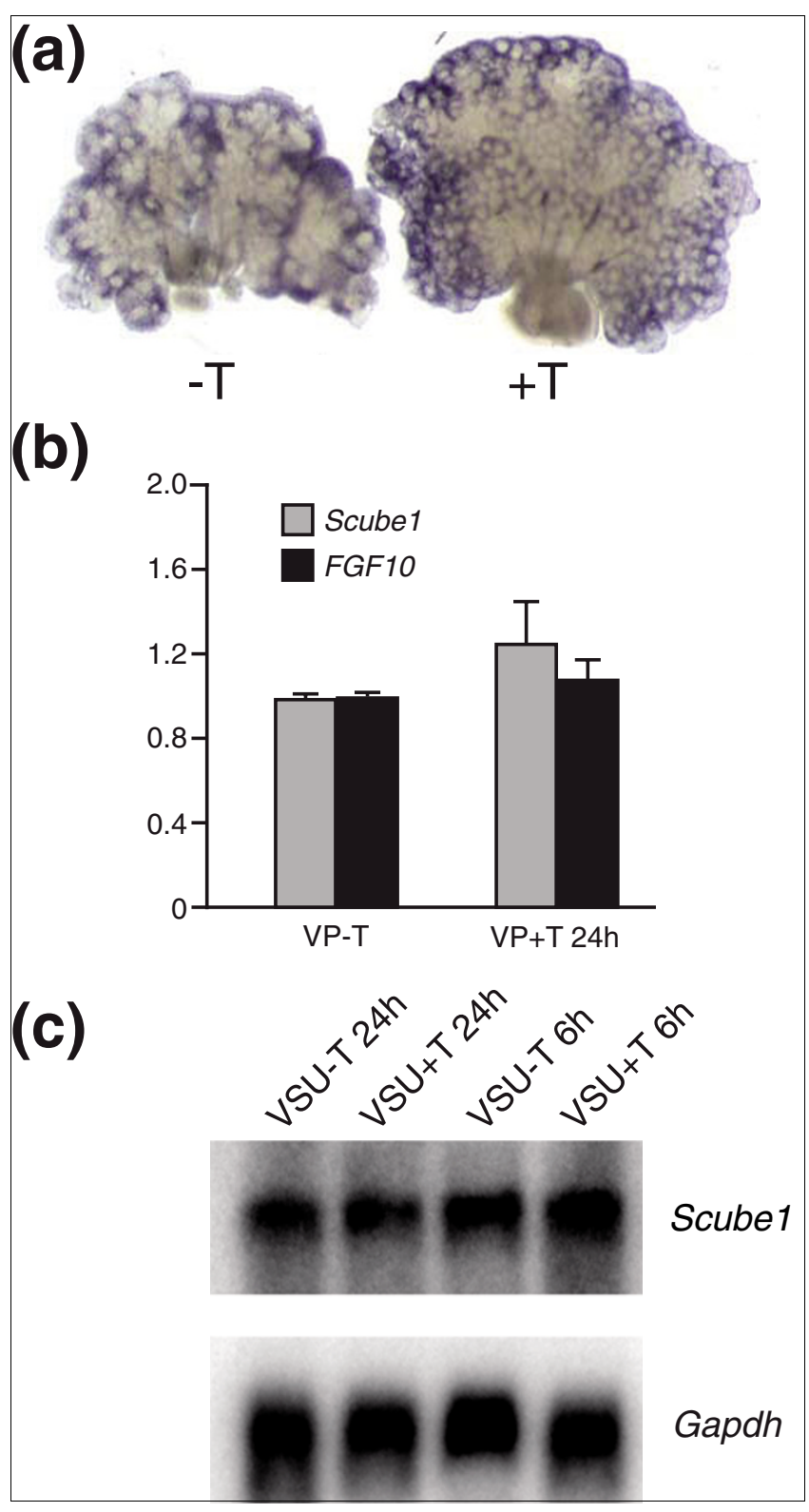

Figure 5

Testosterone does not alter Scubel mRNA levels or expression pattern. (a) Whole-mount RNA in situ hybridization of ventral prostates (VPs) grown in vitro for 6 days in the absence $(-T)$ or presence $(+T)$ of testosterone. (b) Quantitative RT-PCR for Scubel and FGFIO mRNAs in VPs grown in vitro with/without testosterone. VPs were cultured in the absence of testosterone for 3 days followed by an incubation of 24 hours in the presence or absence of testosterone. (c) Northern analysis for Scube I mRNA on PO female urogenital tracts treated in vitro with testosterone for 6 hours and 24 hours. VSU, ventral mesenchymal pad, smooth muscle, urethra.

pared with NPFs could have been caused by loss of a specific subset of cells in the CAF culture versus the NPF culture. However, because these cell populations are stable in culture and this effect is observed in different sets of patient matched NPFs/CAFs, we propose that the difference in expression between the cell populations is most likely caused by specific 


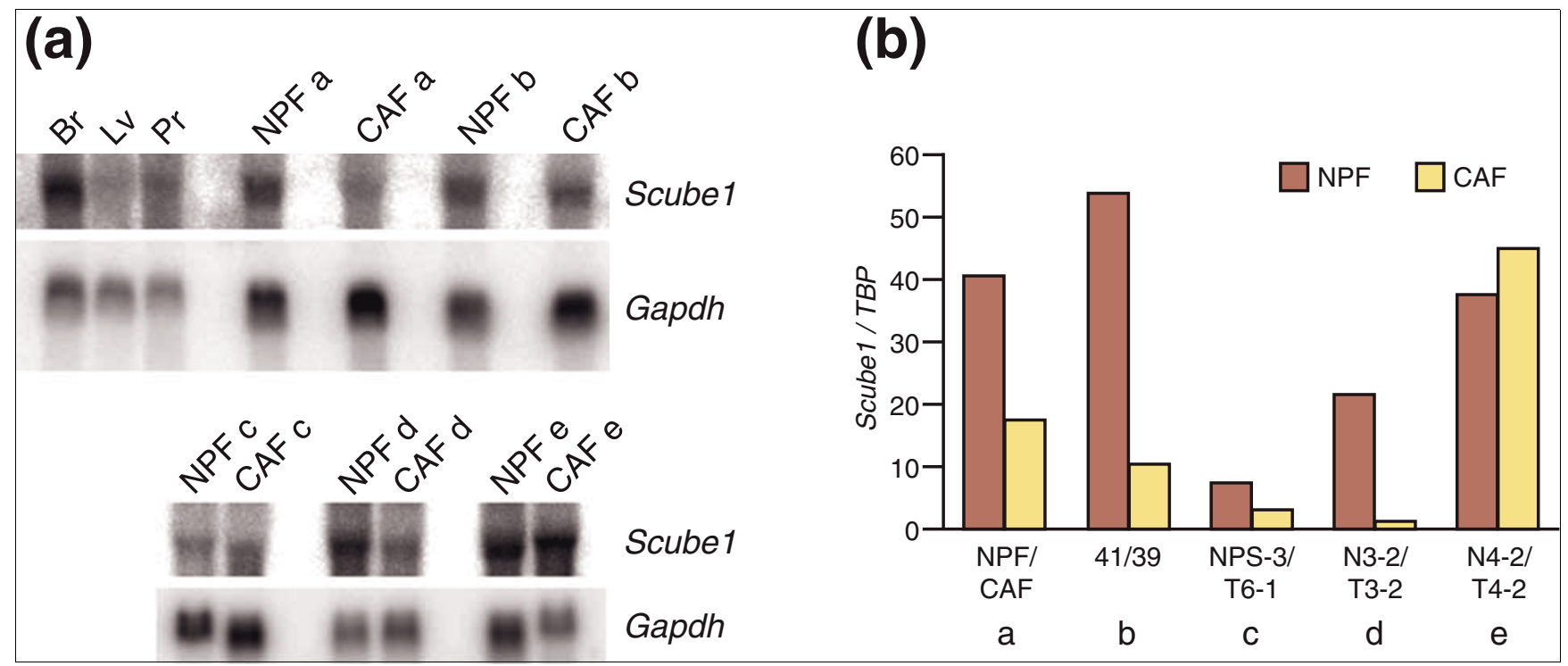

\section{Figure 6}

Expression of Scubel mRNA in prostate tumor stromal cells using CAFs and NPFs. (a) Northern analysis of Scube I mRNA in five pairs (a to e) of cancerassociated fibroblasts (CAFs)/normal prostate fibroblasts (NPFs). Embryonic human brain, liver, and prostate are included as control tissues, and RNA loading is illustrated by hybridization with Gapdh. Scube I mRNA was lower in CAFs in four out of five CAF/NPF pairs. (b) The downregulation of Scube I mRNA in CAFs was confirmed by quantitative RT-PCR; Scube I mRNA levels were normalized to TBP mRNA levels. Br, brain; Lv, liver; Pr, prostate.

loss of Scube1 expression in CAFs either by downregulation or by loss of the chromosomal region. The same samples were also checked for CXC chemokine ligand (CXCL)12 mRNA levels; CXCL12 has been identified as a stromal molecule that stimulates tumorigenesis [43]. In four of five samples, CXCL12 was found to be upregulated in the CAFs (data not shown), similar to reported findings in breast tumor stroma [44].

\section{Discussion}

In this study we provide a detailed molecular profile of a subset of the mesenchymal cell compartment, the VMP, which controls prostatic organ induction and development. The UGM/urogenital stroma is a very potent tissue during both development and disease, which has been demonstrated by tissue recombination experiments. Androgen action in the UGM has been shown to be necessary and sufficient for prostatic development (for review [1]). When recombined with human embryonic stem cells, the UGM directs differentiation into mature human prostate tissue expressing prostate-specific antigen [45]. Furthermore, embryonic UGM has the ability to re-differentiate prostate cancer cells and to reduce tumor growth [46]. It has recently emerged that the stroma can initiate and stimulate prostate tumorigenesis [25-27,47], and profiling of tumor stroma has identified developmental molecules such as secreted frizzled-related protein 2 [28]. Because of the restricted expression of Scube1 in a small subset of cells, it would be very difficult to identify Scube1 in a profiling screen of heterogeneous tissue samples such as tumors unless it was significantly upregulated during tumor- igenesis. Hence, a transcript profile of a potent tissue such as the VMP not only provides us with potential new regulators of prostate growth, but it may also highlight some that could regulate neoplastic growth.

For our analysis we used the inductive mesenchyme of a female UGT and assumed that key prostatic regulators may not be induced by testosterone [48]. We also reasoned that a highly sensitive gene profiling approach might detect androgen-regulated molecules at their 'un-induced' levels, in the event that some stromal mediators might be upregulated by androgens. Most profiling studies have focused on pathways activated by androgens to find new regulators of prostate growth [12-15]. However, none of these studies has successfully identified molecules that satisfy the criteria of being 'andromedins'. At present no growth factors expressed in the UGM have been shown to be directly regulated by androgens. We hypothesized that key prostatic inducers are constitutively expressed in the inductive mesenchyme, regardless of testosterone levels, and that by profiling the VMP novel growth regulatory signaling pathways would be identified. We have previously suggested that molecules produced by, or in, the VMP may be indirectly regulated by an androgen sensitive layer of smooth muscle that forms a separating layer between the VMP and the urethral epithelia [8,9].

To identify VMP-specific transcripts from our VMP SAGE data, we employed a novel strategy. We compared the VMPonly SAGE library with a more complex SAGE library of the complete female prostatic precursor (termed VSU). By doing so we specifically focused on low abundance VMP-enriched 
or VMP-restricted transcripts. Additionally, the ability to isolate enough inductive mesenchyme for direct SAGE library construction (without amplification or dilution with other cell types) indicates that our VMP library may contain a number of important and potent molecules that are absent or poorly represented in current datasets, because these are typically made from tissues composed of many cell types. Profiling of the VMP, which is highly enriched for growth regulatory proteins such as FGFs, yielded a number of extracellular and transmembrane proteins with putative growth regulatory or modulatory functions. The expression of many of these factors in the prostate has not been revealed by other profiling studies, which may be because of their greater cellular complexity or the use of adult tissues in which growth regulatory pathways are less active. We estimate that $30 \%$ to $50 \%$ of the molecules in the VMP list will be experimentally confirmed as being VMP enriched, based on our follow up of 30 candidate molecules. This ratio compares favorably with other profiling studies, but it is inevitable that transcripts will have been missed and that others will not be experimentally confirmed. This is likely because our studies have focused upon low abundance transcripts, which are the most susceptible to sampling error when measured using SAGE.

We identified Scube1 as a prostatic inductive mesenchyme specific molecule. The temporal and spatial expression pattern of Scube1 during prostate organogenesis is coincident with prostate induction and subsequent branching morphogenesis. In developing ventral prostates the highest concentration of Scube1 transcript was localized to the mesenchymal cells adjacent to the distal duct tips. This localization to the distal mesenchyme mirrors the localization of $\mathrm{Fg} f 1 \mathrm{O}$ and suggests an involvement of Scube1 in ductal growth. Interestingly the Shh receptor Ptc also localizes to this inductive mesenchyme [11]. Although no function has yet been described for Scube1, its family member Scube2, is reported to be involved in Shh signal transduction [39,40,49]. Studies in zebrafish highlighted Scube2 as an essential mediator of hedgehog (Hh) signaling with a role in stabilization or transport of the Hh protein, or a role in the endocytotic uptake of Shh [40,49]. During prostate development, Shh signaling regulates ductal growth and branching, although it is not essential for prostate induction [50,51]. Shh is composed of prostatic epithelium and acts as a mitogen for the prostatic mesenchyme. Scube1 expression in the target mesenchyme may be required for the mitogenic effects of Shh. Because several components of the Hh pathway are regulated by Shh, we examined whether Scube1 levels in Po UGTs and VPs were affected by Shh treatment. We could not detect any regulation of Scube1 transcript expression by recombinant Shh or inhibition of Hh signaling with cyclopamine (data not shown). It is possible that Scube may regulate other signaling pathways because it is expressed in areas where Hh signaling is not thought to be important. Studies in zebrafish also suggested that Scube family members may modulate BMP activity [39]. To determine the function of SCUBE1 protein, we have attempted to purify recombinant $S C U B E 1$, but in our studies it appeared that SCUBE1 became insoluble when purified and we were unable to assess the action of the protein in cell and organ culture studies. Scube1 has been detected in vascular endothelial cells, and the protein can form oligomers that are associated with the cell surface [38]. Gene targeting studies or misexpression approaches will be needed to assess the role of Scube1 in prostate organogenesis.

We did not observe any regulation of Scube1 mRNA by androgens in vivo or in vitro, and therefore it is unlikely that Scube1 functions as an andromedin. Both Fgf1O and Fgf7 are important regulators of prostate growth and neither is androgen regulated in vivo. It is likely that there is a group of molecules important in prostate growth that are not regulated by androgens. Scube1 has not been identified in profiling studies looking for androgen regulated mediators of prostate growth, and it seems probable that Scube1 is not a direct mediator of androgen action. Scube1 specific tags are present in SAGE libraries made from mouse E16.5 UGM [37]. In the study conducted by Zhang and coworkers [37] the tag count for Scube1 was lower than that in our study, and Scube1 would not have been identified as inductive mesenchyme specific, because those authors did not profile subsets of the mesencyhmal compartment. Because of the restricted expression of Scube1 in a small subset of cells and the low abundance of this transcript, it would be very difficult to identify Scube1 in a profiling screen using whole prostate organs or a complex tissue such as tumors.

We showed that Scube1 is expressed in both prostate development and prostate cancer stromal cells, which concurs with the observation that many developmental pathways are involved in tumorigenesis. The downregulation of Scube1 in CAFs compared with NPFs suggests that it may function as a tumor suppressor, although this remains to be experimentally confirmed. Scube1 is located on human chromosome 22q13, and this region is reported to be deleted in some prostate cancer samples $[52,53]$, which supports the notion that Scube1 may function as a tumor suppressor. The region $22 \mathrm{q} 13$ contains approximately 242 genes, and thus genes other than Scube1 may be acting as tumor suppressors. Also, it is not known whether the deletion of 22q13 is present in stroma or epithelia within the tumor samples. Although we do not know whether Scube1 is expressed in epithelia, there is no indication that it is expressed in epithelia during development and it appears to be absent from some prostate epithelial cell lines (Vanpoucke G, Thomson AA, unpublished data). Scube1 has not been observed in prostate cancer using whole tumor profiling studies [54,55], perhaps because it is expressed in a small subset of cells within the tumor that are not well represented in whole tumor gene signatures. The only way to identify molecules in small subsets of tumor will be to increase the efficiency of whole tumor profiles (by increasing the sampling level) or to isolate subsets of the tumors for profiling [44]. We have identified tumor expression of Scube1 using a candidate- 
based approach, based upon its expression in a subset of mesenchyme that is known to be important in prostate development.

Our study identified several additional signaling molecules that were expressed in the inductive mesenchyme, which have the potential to act either as paracrine regulators of the prostatic epithelium or as mediators of reciprocal epithelialmesenchymal signaling during prostate organogenesis. Estradiol-induced gene 4 (E2IG4) was originally identified in a screen for estrogen responsive genes [56]. Furthermore, it is the mammalian ortholog of chicken Tsukushi, which is a BMP inhibitor that is involved in organizer induction [57]. Dlk-1 is known as a de-differentiation factor from studies of adipogenesis [58]. Its expression in prostate mesenchyme has not previously been reported, but it was observed in a SAGE screen for stromal changes in breast cancer [44]. Nell2 is a secreted epidermal growth factor family member; no function has been described for this protein, but it was shown to be over-expressed in benign prostatic hyperplasia [59]. Sprouty is a negative regulator of FGFs and its expression is reported to be decreased in prostate cancer [6o]. Members of the Slit, Semaphorin, and Ephrin families of proteins are best known for their role as guidance cues for axons (for review [61]), but recent studies show that they contribute to the development of a variety of organs. Slit2 plays a key role during kidney development in positioning the site of kidney induction [62].

\section{Conclusion}

We identified Scube1 as a novel prostatic inductive mesenchyme specific molecule with potential roles in prostate development and disease. Furthermore, our VMP-specific SAGE list gives an overview of the transcriptional programs active in a key subset of the mesenchyme during prostate induction. This detailed analysis of the developmental pathways that control normal prostate morphogenesis can also provide insights into the regulatory pathways that control neoplastic growth.

\section{Materials and methods \\ RNA isolation and SAGE library construction}

Whole prostatic precursors (VSUs) and VMPs were microdissected from female postnatal day o (Po) outbred Wistar rats. RNA was extracted from 100 pooled VSUs and 90 VMPs using the RNeasy Mini kit (Qiagen, Crawley, UK). RNA quality and concentration was measured using an Agilent (Santa Clara, CA, USA) 2100 Bioanalyser; $50 \mu \mathrm{g}$ VSU total RNA and $20 \mu \mathrm{g}$ of VMP total RNA were used. Long-SAGE libraries were constructed using the I-SAGE kit (Invitrogen, Carlsbad, CA, USA) protocol adapted for LongSAGE according to the LongSAGE protocol (released by Genzyme, Cambridge, MA, USA, January 2003). NlaIII and MmeI were used as the anchoring and tagging restriction enzymes, respectively. Before ligation into the pZERO-1 vector, concatemers were digested with
SphI to improve their cloning efficiency. The VMP and VSU SAGE libraries contained 80,790 and 70,395 tags (respectively) and are shown in Additional data files 2 and 3 (Gene Expression Omnibus accession number GSE7899).

\section{Bioinformatic analysis of SAGE data}

Long-SAGE tags were extracted from the raw sequence files, filtered, and tabulated using SAGE200o software (version 4.5) [63]. During this process linker sequences and duplicate dimers were removed from the sequence data. For the VMP and Po UGT pair-wise library comparison, a tag was tested for significance using the Audic and Claverie [32,64] and the Ztest (Statview software package, Letchworth, UK). A 95\% confidence interval was applied $(P<0.05)$. Both statistical tests gave similar results. Tag to gene annotations were done using the rat Long-SAGE map reference database [65]. When no gene was assigned with a tag, a genomic BLAST was performed with the complete 21 base pair tag sequence (CATG-17bp tag) using the ENSEMBL rat genome browser to aid in gene assignment [66]. When a tag gave a unique hit in the rat genome within 5 kilobases from an assigned locus, we hypothesized that the tag originated from this transcript. This manual tag mapping was verified for a number of transcripts by performing rapid amplifications of cDNA 3 ' ends (3'RACE) experiments [67]. The assignment of molecular function of the genes was done using the Gene Ontology database and Genecards $[68,69]$.

\section{Quantitative RT-PCR and Northern analyses}

Quantitative RT-PCR and Northern analysis were performed to validate the SAGE data, using several independent isolates of VMP and VSU RNA. PCRs were performed on the Lightcycler using the Lightcycler FastStart DNA master SYBRGreen kit (Roche, Burgess Hill, UK). Primer pairs were designed to amplify the genes summarized in Table 2.

The amplified PCR products were used as template for DNA probe synthesis for Northern hybridization. DNA probes were labeled using the Radprime DNA labeling kit (Invitrogen) in the presence of $\alpha^{32} \mathrm{P}$ dCTP. Transcript abundances were normalized to either TBP or Gapdh housekeeping gene.

\section{Whole-mount RNA in situ hybridization}

A 739 base pair fragment corresponding to nucleotides 2,258 to 2,996 from rScube1 (XM_235529) was amplified and cloned into the pCR4-TOPO vector (Invitrogen). Sense and anti-sense probes were transcribed and labeled with digoxigenin using $\mathrm{T}_{7}$ and $\mathrm{T}_{3}$ RNA polymerase. Dissected tissues were fixed in $4 \%$ paraformaldehyde at $4^{\circ} \mathrm{C}$ overnight, dehydrated through graded methanol, and stored in $100 \%$ methanol at $-20^{\circ} \mathrm{C}$. RNA in situ hybridization on embryonic and Po UGTs and cultured ventral prostates were performed using the InsituPro VS robot (Intavis, Bioanalytical Instruments AG, Cologne, Germany). After rehydration tissues were bleached in $6 \%$ hydrogen peroxide, treated with $20 \mu \mathrm{g} /$ $\mathrm{ml}$ proteinase $\mathrm{K}$ for up to 1 hour and refixed in $4 \%$ parafor- 
Table 2

Primer pairs used in the present study

\begin{tabular}{lll}
\hline Gene & Forward primer & Reverse primer \\
\hline rScubel & GTTCTCCAGGCTTCTTCTCAGAG & TACAGTGGGCAGAGCATTGG \\
rFGFIO & CAGTGGAAATCGGAGTTGTTG & ATGACGCAATGACACAGAGCT \\
rTBP & GCGGTTTGGCTAGGTTTCTG & CCTAGAGCATCCTCTTATCTCCT \\
hSCUBEI & ATTTGTAGGGCCGCAGGAAC & CGAGTCTGGCACGAAGAGTG \\
hGapdh & TTAGCACCCCTGGCCAAGG & CTTACTCCTTGGAGGCCATG \\
\hline
\end{tabular}

maldehyde/o.2\% glutaraldehyde. Hybridization with digoxigenin-labeled probes was performed at $65^{\circ} \mathrm{C}$ for 16 hours, followed by high stringency washes. For detection tissues were incubated with anti-digoxigenin antibody conjugated to alkaline phosphatase (Roche, Burgess Hill, UK; 1/2,000) at $18^{\circ} \mathrm{C}$ for 6 hours. After washing, the color was developed using NBT/BCIP solution. Typical development times were around 8 hours.

\section{Organ culture and in vitro testosterone treatments}

Po VPs were cultured for 6 days in presence or absence of $10^{-}$ $8 \mathrm{~mol} / \mathrm{l}$ testosterone, as previously described [7], before whole-mount in situ hybridization. Additionally, Po VPs were cultured in the absence of testosterone for 3 days, followed by 24 hours of treatment with testosterone and subsequent RNA preparation. Po female UGTs were cultured under similar conditions and treated with testosterone for 6 or 24 hours, followed by RNA isolation.

\section{Culture of CAFs and NPFs}

Cells were isolated and grown as described by Olumi and coworkers [26]. Prostate tissue was cut into 1 to $2 \mathrm{~mm}^{3}$ pieces and treated with collagenase type I (225 units/ml; Sigma) and hyaluronidase (125 units/ml; Sigma) in RPMI 1640 (with 10\% fetal calf serum) overnight at $37^{\circ} \mathrm{C}$. Cells were washed twice with media, plated, and grown until approximately 50\% confluence. Stromal cells were selected using differential trypsinization, with $0.05 \%$ Trypsin, to remove only the stromal cells, which were subsequently passaged two or three times. Immunohistochemistry for vimentin and smooth muscle $\alpha$-actin were used as stromal markers, and epithelial contamination was excluded using pan-cytokeratin staining. $\mathrm{CAF}$ and NPF cells were recombined with $\mathrm{BPH} 1$ cells to determine tumorigenic activity [26].

\section{Abbreviations}

BLAST, basic local alignment search tool; BMP, bone morphogenetic protein; CAF, cancer-associated fibroblast; CXCL, CXC chemokine ligand; FGF, fibroblast growth factor; $\mathrm{Hh}$, hedgehog; NPF, normal prostate fibroblast; RT-PCR, reverse transcription polymerase chain reaction; SAGE, serial analysis of gene expression; Shh, sonic hedgehog; UGM, urogenital mesenchyme; UGS, urogenital sinus; UGT, urogenital tract;
VMP, ventral mesenchymal pad; VP, ventral prostate; VSU, VMP, smooth muscle and urethral epithelium.

\section{Authors' contributions}

GV designed and executed experiments and wrote an initial version of the manuscript. BO constructed the SAGE libraries, with assistance from OCG and RC. GV, BO and GRA identified candidate molecules from the SAGE libraries and performed follow-up studies on these molecules. KW, OFE and SWH isolated and tested the CAF/NPF primary cultures. AAT conceived the study, supervised the work and wrote the manuscript. All authors read and approved the manuscript.

\section{Additional data files}

The following additional data are available with the online version of this paper. Additional data file 1 contains the list of transcripts exhibiting a statistically significant difference between the VMP and VSU libraries. Additional data file 2 is the tab delimited text file of the VMP SAGE library. Additional data file 3 is the tab delimited text file of the VSU SAGE library.

\section{Acknowledgements}

We should like to thank Lee Smith for comments on the manuscript, Mark Fisken for technical assistance, and Kevin Morgan for help with bioinformatics. We should also like to acknowledge the Southern Prostate Collaborative of the National Cancer Research Institute (UK) for funding in the initial stages of the project, and the Medical Research Council for the majority of the funding. We would like to thank Prof Nick Hastie and the MRC Human Genetics Unit for advice and assistance in sequencing the SAGE libraries.

\section{References}

I. Marker PC, Donjacour AA, Dahiya R, Cunha GR: Hormonal, cellular, and molecular control of prostatic development. Dev Biol 2003, 253:165-174.

2. Cunha GR, Ricke W, Thomson A, Marker PC, Risbridger G, Hayward SW, Wang YZ, Donjacour AA, Kurita T: Hormonal, cellular, and molecular regulation of normal and neoplastic prostatic development. I Steroid Biochem Mol Biol 2004, 92:22I-236.

3. Cunha GR, Chung LW: Stromal-epithelial interactions--I. Induction of prostatic phenotype in urothelium of testicular feminized (Tfm/y) mice. J Steroid Biochem 198I, 14:1317-1324.

4. Cunha GR, Lung B: The possible influence of temporal factors in androgenic responsiveness of urogenital tissue recombinants from wild-type and androgen-insensitive ( $\mathrm{Tfm})$ mice. J Exp Zool 1978, 205:18I-193. 
5. Timms BG, Lee CW, Aumuller G, Seitz J: Instructive induction of prostate growth and differentiation by a defined urogenital sinus mesenchyme. Microsc Res Tech 1995, 30:319-332.

6. Lamm ML, Podlasek CA, Barnett DH, Lee J, Clemens JQ, Hebner CM, Bushman W: Mesenchymal factor bone morphogenetic protein 4 restricts ductal budding and branching morphogenesis in the developing prostate. Dev Biol 200I, 232:30I-3I4.

7. Thomson AA, Cunha GR: Prostatic growth and development are regulated by FGFI 0. Development 1999, I 26:3693-370I.

8. Thomson AA, Timms BG, Barton L, Cunha GR, Grace OC: The role of smooth muscle in regulating prostatic induction. Development 2002, 129:1905-1912.

9. Chrisman $H$, Thomson AA: Regulation of urogenital smooth muscle patterning by testosterone and estrogen during prostatic induction. Prostate 2006, 66:696-707.

10. Donjacour AA, Thomson AA, Cunha GR: FGF-10 plays an essential role in the growth of the fetal prostate. Dev Biol 2003, 26I:39-54.

II. Pu Y, Huang L, Prins GS: Sonic hedgehog-patched Gli signaling in the developing rat prostate gland: lobe-specific suppression by neonatal estrogens reduces ductal growth and branching. Dev Biol 2004, 273:257-275.

12. Abbott DE, Pritchard C, Clegg NJ, Ferguson C, Dumpit R, Sikes RA, Nelson PS: Expressed sequence tag profiling identifies developmental and anatomic partitioning of gene expression in the mouse prostate. Genome Biol 2003, 4:R79.

13. Berquin IM, Min Y, Wu R, Wu H, Chen YQ: Expression signature of the mouse prostate. J Biol Chem 2005, 280:36442-3645I.

14. Nantermet PV, Xu J, Yu Y, Hodor P, Holder D, Adamski S, Gentile MA, Kimmel DB, Harada S, Gerhold D, et al.: Identification of genetic pathways activated by the androgen receptor during the induction of proliferation in the ventral prostate gland. J Biol Chem 2004, 279: I310-1322.

15. Pang ST, Dillner K, Wu X, Pousette A, Norstedt G, Flores-Morales A: Gene expression profiling of androgen deficiency predicts a pathway of prostate apoptosis that involves genes related to oxidative stress. Endocrinology 2002, I 43:4897-4906.

16. Dhanasekaran SM, Barrette TR, Ghosh D, Shah R, Varambally S, Kurachi K, Pienta KJ, Rubin MA, Chinnaiyan AM: Delineation of prognostic biomarkers in prostate cancer. Nature 200I, 4I 2:822-826.

17. Lapointe J, Li C, Higgins JP, van de Rijn M, Bair E, Montgomery K, Ferrari M, Egevad L, Rayford W, Bergerheim U, et al.: Gene expression profiling identifies clinically relevant subtypes of prostate cancer. Proc Natl Acad Sci USA 2004, 10 I:8 I I-816.

18. Luo J, Duggan DJ, Chen Y, Sauvageot J, Ewing CM, Bittner ML, Trent $J M$, Isaacs WB: Human prostate cancer and benign prostatic hyperplasia: molecular dissection by gene expression profiling. Cancer Res 200I, 6I:4683-4688.

19. Waghray A, Schober M, Feroze F, Yao F, Virgin J, Chen YQ: Identification of differentially expressed genes by serial analysis of gene expression in human prostate cancer. Cancer Res 200I, 6I:4283-4286.

20. Segawa T, Nau ME, Xu LL, Chilukuri RN, Makarem M, Zhang W, Petrovics G, Sesterhenn IA, McLeod DG, Moul JW, et al.: Androgeninduced expression of endoplasmic reticulum (ER) stress response genes in prostate cancer cells. Oncogene 2002, 21:8749-8758.

21. Stuart RO, Wachsman W, Berry CC, Wang-Rodriguez J, Wasserman L, Klacansky I, Masys D, Arden K, Goodison S, McClelland M, et al.: In silico dissection of cell-type-associated patterns of gene expression in prostate cancer. Proc Natl Acad Sci USA 2004, 101:615-620.

22. Bhowmick NA, Neilson EG, Moses HL: Stromal fibroblasts in cancer initiation and progression. Nature 2004, 432:332-337.

23. Cunha GR, Hayward SW, Wang YZ: Role of stroma in carcinogenesis of the prostate. Differentiation 2002, 70:473-485.

24. Tuxhorn JA, Ayala GE, Rowley DR: Reactive stroma in prostate cancer progression. J Urol 200I, 166:2472-2483.

25. Barclay WW, Woodruff RD, Hall MC, Cramer SD: A system for studying epithelial-stromal interactions reveals distinct inductive abilities of stromal cells from benign prostatic hyperplasia and prostate cancer. Endocrinology 2005, I 46: I3-18.

26. Olumi AF, Grossfeld GD, Hayward SW, Carroll PR, Tlsty TD, Cunha GR: Carcinoma-associated fibroblasts direct tumor progression of initiated human prostatic epithelium. Cancer Res 1999, 59:5002-50II.

27. Tuxhorn JA, McAlhany SJ, Dang TD, Ayala GE, Rowley DR: Stromal cells promote angiogenesis and growth of human prostate tumors in a differential reactive stroma (DRS) xenograft model. Cancer Res 2002, 62:3298-3307.

28. Joesting MS, Perrin S, Elenbaas B, Fawell SE, Rubin JS, Franco OE, Hayward SW, Cunha GR, Marker PC: Identification of SFRPI as a candidate mediator of stromal-to-epithelial signaling in prostate cancer. Cancer Res 2005, 65:10423-10430.

29. Pierce GB: On the boundary between development and neoplasia. An interview with Professor G. Barry Pierce. Interview by Juan Arechaga. Int J Dev Biol 1993, 37:5-16.

30. Velculescu VE, Zhang L, Vogelstein B, Kinzler KW: Serial analysis of gene expression. Science 1995, 270:484-487.

31. Grimmond S, Larder R, Van Hateren N, Siggers P, Hulsebos TJ, Arkell $R$, Greenfield $A$ : Cloning, mapping, and expression analysis of a gene encoding a novel mammalian EGF-related protein (SCUBEI). Genomics 2000, 70:74-8I.

32. Audic $S$, Claverie JM: The significance of digital gene expression profiles. Genome Res 1997, 7:986-995.

33. Man MZ, Wang X, Wang Y: POWER_SAGE: comparing statistical tests for SAGE experiments. Bioinformatics 2000, 16:953-959.

34. Ruijter JM, Van Kampen AH, Baas F: Statistical evaluation of SAGE libraries: consequences for experimental design. Physiol Genomics 2002, I I:37-44.

35. Baker J, Hardy MP, Zhou J, Bondy C, Lupu F, Bellve AR, Efstratiadis A: Effects of an IgfI gene null mutation on mouse reproduction. Mol Endocrinol 1996, 10:903-918.

36. Ruan W, Powell-Braxton L, Kopchick JJ, Kleinberg DL: Evidence that insulin-like growth factor I and growth hormone are required for prostate gland development. Endocrinology 1999 , I 40:1984-1989.

37. Zhang TJ, Hoffman BG, Ruiz de Algara T, Helgason CD: SAGE reveals expression of Wnt signalling pathway members during mouse prostate development. Gene Expr Patterns 2006, 6:310-324.

38. Yang RB, Ng CK, Wasserman SM, Colman SD, Shenoy S, Mehraban F, Komuves LG, Tomlinson JE, Topper JN: Identification of a novel family of cell-surface proteins expressed in human vascular endothelium. J Biol Chem 2002, 277:46364-46373.

39. Kawakami A, Nojima Y, Toyoda A, Takahoko M, Satoh M, Tanaka H, Wada H, Masai I, Terasaki H, Sakaki Y, et al.: The zebrafishsecreted matrix protein you/scube2 is implicated in longrange regulation of hedgehog signaling. Curr Biol 2005, 15:480-488.

40. Woods IG, Talbot WS: The you gene encodes an EGF-CUB protein essential for Hedgehog signaling in zebrafish. PLOS Biol 2005, 3:e66.

4I. Sugimura Y, Cunha GR, Donjacour AA, Bigsby RM, Brody JR: Wholemount autoradiography study of DNA synthetic activity during postnatal development and androgen-induced regeneration in the mouse prostate. Biol Reprod 1986, 34:985-995

42. Tomlinson DC, Grindley JC, Thomson AA: Regulation of Fgf IO gene expression in the prostate: identification of transforming growth factor-betal and promoter elements. Endocrinology 2004, I 45: 1988-1995.

43. Orimo A, Gupta PB, Sgroi DC, Arenzana-Seisdedos F, Delaunay T, Naeem R, Carey VJ, Richardson AL, Weinberg RA: Stromal fibroblasts present in invasive human breast carcinomas promote tumor growth and angiogenesis through elevated SDF-I/ CXCLI 2 secretion. Cell 2005, I 2 I:335-348.

44. Allinen M, Beroukhim R, Cai L, Brennan C, Lahti-Domenici J, Huang $\mathrm{H}$, Porter $\mathrm{D}, \mathrm{Hu}$ M, Chin L, Richardson A, et al:: Molecular characterization of the tumor microenvironment in breast cancer. Cancer Cell 2004, 6: 17-32.

45. Taylor RA, Cowin PA, Cunha GR, Pera M, Trounson AO, Pedersen J, Risbridger GP: Formation of human prostate tissue from embryonic stem cells. Nat Methods 2006, 3:179-181.

46. Hayashi N, Cunha GR: Mesenchyme-induced changes in the neoplastic characteristics of the Dunning prostatic adenocarcinoma. Cancer Res 1991, 5 I:4924-4930.

47. Bhowmick NA, Chytil A, Plieth D, Gorska AE, Dumont N, Shappell S, Washington MK, Neilson EG, Moses HL: TGF-beta signaling in fibroblasts modulates the oncogenic potential of adjacent epithelia. Science 2004, 303:848-851.

48. Thomson AA: Role of androgens and fibroblast growth factors in prostatic development. Reproduction 200I, I 21 : I87-195.

49. Hollway GE, Maule J, Gautier P, Evans TM, Keenan DG, Lohs C, Fischer D, Wicking C, Currie PD: Scube2 mediates Hedgehog 
signalling in the zebrafish embryo. Dev Biol 2006, 294: I04-II8.

50. Freestone SH, Marker P, Grace OC, Tomlinson DC, Cunha GR, Harnden $P$, Thomson AA: Sonic hedgehog regulates prostatic growth and epithelial differentiation. Dev Biol 2003 , 264:352-362.

5I. Berman DM, Desai N, Wang X, Karhadkar SS, Reynon M, Abate-Shen $C$, Beachy PA, Shen MM: Roles for Hedgehog signaling in androgen production and prostate ductal morphogenesis. Dev Biol 2004, 267:387-398.

52. Nupponen NN, Kakkola L, Koivisto P, Visakorpi T: Genetic alterations in hormone-refractory recurrent prostate carcinomas. Am J Pathol 1998, 153:14I-148.

53. Wolf MK, Edgren H, Mills I, Carles A, Poch O, Kilpinen S, Peltola M, Autio R, Neal D, Wasylyk B, et al.: Integrated DNA/RNA microarray profiling of hormone-refractory clinical prostate cancers and metastases indicates deregulation of several pathways, including androgen/AR, Hedgehog, MAPK and neuroactive ligand/receptor signalling [abstract]. In Proceedings of the 97th Annual Meeting of the American Association for Cancer Research; 2006 April 1-5; Washington DC Philadelphia (PA): AACR 2006:36. Abstract nr 153. AACR Meeting Abstracts 2006, 2006: 36-a-

54. Oncomine: Cancer Profiling Database [http://www.oncom ine.org/main/index.jsp]

55. Rhodes DR, Yu J, Shanker K, Deshpande N, Varambally R, Ghosh D, Barrette T, Pandey A, Chinnaiyan AM: ONCOMINE: a cancer microarray database and integrated data-mining platform. Neoplasia 2004, 6: I-6.

56. Charpentier AH, Bednarek AK, Daniel RL, Hawkins KA, Laflin KJ, Gaddis S, MacLeod MC, Aldaz CM: Effects of estrogen on global gene expression: identification of novel targets of estrogen action. Cancer Res 2000, 60:5977-5983.

57. Ohta K, Lupo G, Kuriyama S, Keynes R, Holt CE, Harris WA, Tanaka $H$, Ohnuma S: Tsukushi functions as an organizer inducer by inhibition of BMP activity in cooperation with chordin. Dev Cell 2004, 7:347-358.

58. Smas CM, Sul HS: Pref-I, a protein containing EGF-like repeats, inhibits adipocyte differentiation. Cell 1993, 73:725-734.

59. DiLella AG, Toner TJ, Austin CP, Connolly BM: Identification of genes differentially expressed in benign prostatic hyperplasia. J Histochem Cytochem 200I, 49:669-670.

60. Kwabi-Addo B, Wang J, Erdem H, Vaid A, Castro P, Ayala G, Ittmann $M$ : The expression of Sproutyl, an inhibitor of fibroblast growth factor signal transduction, is decreased in human prostate cancer. Cancer Res 2004, 64:4728-4735.

61. Hinck $L$ : The versatile roles of 'axon guidance' cues in tissue morphogenesis. Dev Cell 2004, 7:783-793.

62. Grieshammer U, Le Ma, Plump AS, Wang F, Tessier-Lavigne M, Martin GR: SLIT2-mediated ROBO2 signaling restricts kidney induction to a single site. Dev Cell 2004, 6:709-717.

63. Serial Analysis of Gene Expression [http://www.sagenet.org]

64. Significance of digital gene expression profiles [http:// www.igs.cnrs-mrs.fr/Winflat/winflat.cgi]

65. NCBI SAGEmap [http://www.ncbi.nlm.nih.gov/projects/SAGE/]

66. Ensemble Genome Browser [http://www.ensemblorg/
[ index.html]

67. Chen JJ, Rowley JD, Wang SM: Generation of longer cDNA fragments from serial analysis of gene expression tags for gene identification. Proc Natl Acad Sci USA 2000, 97:349-353.

68. The Gene Ontology [http://geneontology.org/]

69. GeneCards [http://www.genecards.org] 